\title{
Investigation of Factors Affecting Friction Stir Welding of Polyethylene by ANOVA Analysis
}

\author{
Mustafa Kemal BILICI ${ }^{1}$ *, Ahmet Irfan YUKLER ${ }^{2}$, Memduh KURTULMUS ${ }^{1}$, \\ İlyas KARTAL ${ }^{3}$
}

\author{
${ }^{1}$ Marmara University, School of Applied Sciences, Goztepe Campus, Istanbul, Turkey \\ ${ }^{2}$ Nisantasi University, Faculty of Engineering, Maslak Campus, Istanbul, Turkey \\ ${ }^{3}$ Marmara University, Faculty of Technology, Goztepe Campus, Istanbul, Turkey \\ crossref http://dx.doi.org/10.5755/j02.ms.27591
}

Received 07 September 2020; accepted 05 January 2021

\begin{abstract}
The variables that are effective in joining high density polyethylene sheets by friction stir welding (FSW) have been investigated. In order to understand the effects of welding parameters, using Taguchi optimization, tool rotation speed, feed rate, shoulder diameter and pin diameter values were selected in a wide range. The results obtained with Taguchi optimization method were evaluated according to the highest / the best signal-noise ratio. Macro photographs taken crosssectional view taken the weld seam, SEM images and hardness measurements were used to evaluate. As a result of the evaluation, the accuracy of the optimization was found to be approximately $96 \%$. As a result, feed rate and shoulder diameter were determined as the most effective parameter affecting the welding quality and welding performance. These two parameters (shoulder diameter and feed rate) have found to effect of approximately $65 \%$ on tensile strength, weld quality and hardness. Finally, it has obtained that the most effective welding parameter was the shoulder diameter with $40.81 \%$.

Keywords: friction stir welding (FSW), shoulder-pin diameter, tensile strength, ANOVA analysis, optimization, welding of polymer.
\end{abstract}

\section{INTRODUCTION}

Friction stir welding (FSW) is a solid state welding method that was first discovered in 1990 by the TWI institute and was first applied to aluminum parts. The problems encountered in joining aluminum sheets with conventional welding methods were solved by FSW method [1]. This method was first applied to aluminum sheets and have now found application in magnesium, titanium, copper, brass, low carbon steel, stainless steel, aluminum matrix composite materials and plastics [2-10]. Since welding is done in such a wide range of materials, the usage area is increasing day by day in the industry. Low energy consumption, no smoke (environmentally friendly), no light, no additional wires, no distortion in the welding are the most important reasons for using this welding [6]. The factors affecting the welding quality [11], welding performance and formation of the weld in friction stir welding are grouped in Fig. 1.

These factors must be compatible with each other during welding. In order to achieve the friction mixing welding successfully and to obtain optimum strength values, it is necessary to generate the necessary heat and to spread this heat homogeneously in the welding seam direction. The formation of heat during welding varies depending on both welding parameters and tool geometries $[11,12]$. During welding, heat is provided by the shoulder part of the welding tool and the pin. Pin is mixed the material and the shoulder presses the mixed material to keep it in the welding zone. Therefore, the tool geometry / design must be compatible with each other. If the shoulder and tip diameter are compatible with each other, it will have a positive effect on weld quality and stitch area [13].

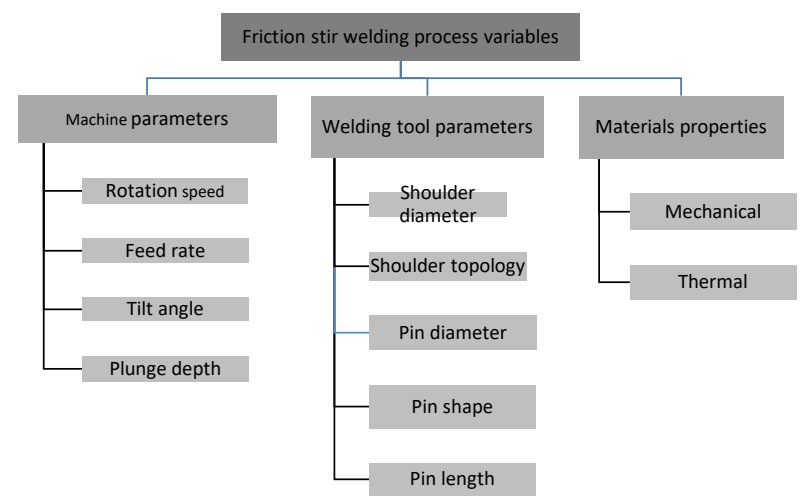

Fig. 1. Factors affecting friction stir welding

The important thing here is to produce some heat. The material mixed due to excessive heat in the welding zone cannot be controlled. Therefore, burr formation occurs. No matter how much pressure the mixed material exerts from the shoulder to the welding area, the material comes out. If the material in the nugget zone is removed, the welding strength will decrease and the seam will deteriorate $[12,13]$. When the ratio between the shoulder diameter and the pin is less than the critical value, insufficient penetration occurs in the welding zone, when large, the formation of burrs due to excessive heat and discontinuities in the seam area occur. If the ratio between the shoulder diameter and the pin diameter

\footnotetext{
* Corresponding author.Tel.: +90-216 7774147.

E-mail address: mkbilici@marmara.edu.tr (M.K. Bilici)
} 
is achieved correct, this time we need to select the correct machine parameters. Although the heat is generated by the shoulder and the pin, the rotational speed of the welding tool and the feed rate advance also aid in heat generation [13]. Producing heat and distributing this heat uniformly throughout the weld seam; shoulder, pin, tool rotation speed and feed rate are needed compatible with each other. If the feed rate is high, it will cause discontinuities and gaps in the weld seam, and if it is in slow contact with the weld seam, material overflow and burr formation will occur. Therefore, the speed of the welding tool and the feed rate must be conformed [14].

In this study, ANOVA analysis was performed with taguchi optimization in order to determine the effect of parameters used in friction mixing welding on welding strength and estimated welding strength values that can be obtained according to welding parameters. Weld joint were evaluated with tensile test, SEM and macro image, shore-D hardness measurements for initial and optimal weld parameters.

\section{EXPERIMENTAL PROCEDURE}

The purpose of the experimental design - the best results in the problems encountered in any process and determining the performance characteristics and examining the factors affecting this feature. Therefore, the experimental design was used to examine the effective factors in FSW. In this way, the experimental conditions is created according to the effective factors in the friction stir welding to be made. Experimental design and analysis were determined by ANOVA analysis using Taguchi method $[15,16]$. Factors and variables affecting FSW are given in Table 1 . With these weld variables Taguchi 4 variables and 4 factors (4x4), L16 source conditions were created [15, 16]. Table 2 shows the welding conditions created by the determined experimental design. Five welds were performed under the specified welding conditions. In this study $4 \mathrm{~mm}$ thick high density polyethylene (HDPE) sheets were used. High density polyethylene (HDPE) sheets were purchased from SIMONA AG, Germany (Tensile stress $22 \mathrm{MPa}$ ). High density polyethylene sheets of $60 \times 150 \mathrm{~mm}$ and $4 \mathrm{~mm}$ thickness were prepared for FSW experiments. As it can be understood from the welding variables given in Table 1 and the test conditions in Table 2, 16 different welding tool were manufactured from SAE 1050 tool steel and heat treated to a hardness of $40 \mathrm{HRC}$. The pin length and shoulder angle of these tools were kept constant. Only the shoulder diameter and pin diameter were changed. In all experiments, the depth of shoulder penetration was $0.2 \mathrm{~mm}$ and kept constant for 20 seconds after dipping $0.2 \mathrm{~mm}$. Welding operations were performed on a universal milling machine with numerical control. For the linear progression of the welding process and the fixing of the parts, the fastening die was designed and manufactured. Thanks to this mold, all welding operations have been carried out as standard. The photograph of the fixing mold is shown in Fig. 2. Tensile tests were carried out according to the standard test method for tensile testing of ASTM D638 Plastics [17]. Welded specimens were tested on an Instron machine at a constant speed of $5 \mathrm{~mm} / \mathrm{s}$. Tensile test results were calculated by averaging five samples. FEI SIRION
SEM device was used to observe the structural changes in the welding area. Shore-D hardness measurements were made according to ASTM D2240 standard and changes in welding regions were observed [18]. In general, the hardness value of the welding regions was obtained by applying the pricking needle for 15 seconds after the sample was placed on a flat surface. Shore hardness value has no unit, it is dimensionless.

Table 1. Factors and variables affecting FSW

\begin{tabular}{|c|c|c|c|}
\hline A & B & C & D \\
\hline $\begin{array}{c}\text { Shoulder } \\
\text { diameter, } \\
\text { mm }\end{array}$ & $\begin{array}{c}\text { Shoulder } \\
\text { diameter/pin } \\
\text { diameter ratio, D/d }\end{array}$ & $\begin{array}{c}\text { Tool } \\
\text { rotation } \\
\text { speed, rpm }\end{array}$ & $\begin{array}{c}\text { Feed rate, } \\
\mathrm{mm} / \text { min }\end{array}$ \\
\hline 14 & 3.0 & 600 & 20 \\
\hline 16 & 3.5 & 900 & 30 \\
\hline 18 & 4.0 & 1100 & 40 \\
\hline 20 & 4.5 & 1500 & 50 \\
\hline
\end{tabular}

Table 2. Experimental conditions with taguchi optimization

\begin{tabular}{|c|c|c|c|c|}
\hline \multicolumn{5}{|c|}{ Experimental conditions } \\
\hline $\begin{array}{c}\text { Experiment } \\
\text { number }\end{array}$ & $\begin{array}{c}\text { Shoulder } \\
\text { diameter, } \\
\text { mm }\end{array}$ & $\begin{array}{c}\text { Shoulder } \\
\text { diameter/pin } \\
\text { diameter ratio }\end{array}$ & $\begin{array}{c}\text { Tool } \\
\text { rotation } \\
\text { speed, rpm }\end{array}$ & $\begin{array}{c}\text { Feed } \\
\text { rate, } \\
\mathrm{mm} / \mathrm{min}\end{array}$ \\
\hline 1 & 14 & $3.0(4.66)$ & 600 & 20 \\
\hline 2 & 14 & $3.5(4.00)$ & 900 & 30 \\
\hline 3 & 14 & $4.0(3.5)$ & 1100 & 40 \\
\hline 4 & 14 & $4.5(3.11)$ & 1500 & 50 \\
\hline 5 & 16 & $3.5(4.47)$ & 1100 & 40 \\
\hline 6 & 16 & $3.0(5.33)$ & 1500 & 50 \\
\hline 7 & 16 & $4.5(3.55)$ & 600 & 20 \\
\hline 8 & 16 & $4.0(4.0)$ & 900 & 30 \\
\hline 9 & 18 & $4.0(4.5)$ & 1500 & 50 \\
\hline 10 & 18 & $4.5(4.0)$ & 1100 & 40 \\
\hline 11 & 18 & $3.0(6.0)$ & 900 & 30 \\
\hline 12 & 18 & $3.5(5.14)$ & 600 & 20 \\
\hline 13 & 20 & $4.5(4.44)$ & 900 & 30 \\
\hline 14 & 20 & $4.0(5.0)$ & 600 & 20 \\
\hline 15 & 20 & $3.5(5.71)$ & 1500 & 50 \\
\hline 16 & 20 & $3.0(6.66)$ & 1100 & 40 \\
\hline
\end{tabular}

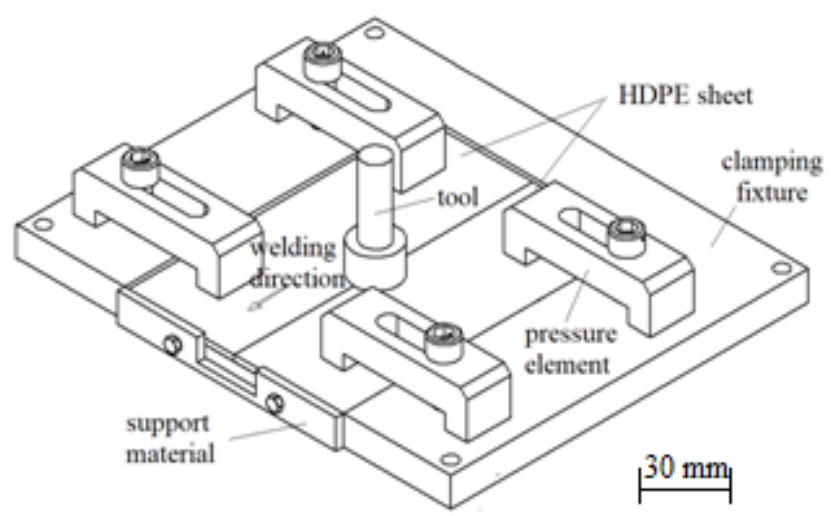

Fig. 2. A properly designed clamping fixture

\section{RESULTS}

Five weld joining were made under 16 different test conditions given in Table 2. Fig. 3 is a view of the weld sample after being joined. As shown in the Fig. 3, the welds were completed any without deformation.

As long as the welding tool continues in the direction of advancement under favorable conditions, there is no 
problem. Only a hole is created at the welding end point. Tensile test results, mean squares deviation (MSD) and the highest-best evaluation method using the signal to noise ratio $(\mathrm{S} / \mathrm{N})$ was obtained. Taguchi uses $\mathrm{S} / \mathrm{N}$ ratio to measure the quality characteristic deviating from the desired value $[15,16]$. The $S / N$ ratio is defined as:

$$
S / N=-10 \log (M S D) \text {, }
$$

where $M S D$ is the mean square deviation for the output characteristic $[15,16]$. Mean square deviation (MSD):

$M S D=\frac{1}{n} \sum_{i=1}^{n} \cdot \frac{1}{T_{\mathrm{i}}^{2}}$,

where $n$ is the number of tests and $T i$ is the value of weld strength of the $i^{\text {th }}$ test.

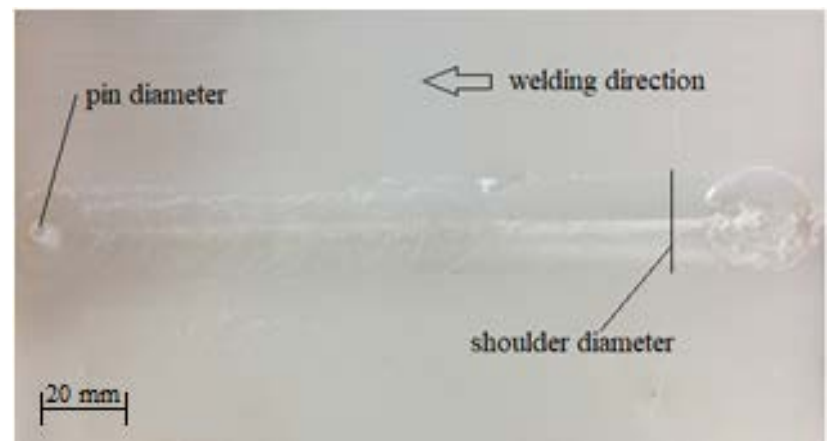

Fig. 3. Image of friction stir welding

Table 3. Tensile strength and signal to noise ratios $(\mathrm{S} / \mathrm{N})$

\begin{tabular}{|c|c|c|}
\hline $\begin{array}{c}\text { Test } \\
\text { number }\end{array}$ & $\begin{array}{c}\text { Tensile } \\
\text { strength, } \\
\text { MPa }\end{array}$ & $\begin{array}{c}\text { S/N } \\
\text { ratio, } \\
\text { dB }\end{array}$ \\
\hline 1 & 11.10 & 20.91 \\
\hline 2 & 8.65 & 18.74 \\
\hline 3 & 11.70 & 21.36 \\
\hline 4 & 8.26 & 18.34 \\
\hline 5 & 11.20 & 20.98 \\
\hline 6 & 7.03 & 16.94 \\
\hline 7 & 8.36 & 18.44 \\
\hline 8 & 15.20 & 23.64 \\
\hline
\end{tabular}

\begin{tabular}{|c|c|c|}
\hline $\begin{array}{c}\text { Test } \\
\text { number }\end{array}$ & $\begin{array}{c}\text { Tensile } \\
\text { strength, } \\
\mathrm{MPa}\end{array}$ & $\begin{array}{c}\mathrm{S} / \mathrm{N} \\
\text { ratio, } \\
\mathrm{dB}\end{array}$ \\
\hline 9 & 6.38 & 16.10 \\
\hline 10 & 9.32 & 19.39 \\
\hline 11 & 9.41 & 19.47 \\
\hline 12 & 7.61 & 17.63 \\
\hline 13 & 8.88 & 18.97 \\
\hline 14 & 11.00 & 20.83 \\
\hline 15 & 14.98 & 23.51 \\
\hline 16 & 11.60 & 21.29 \\
\hline
\end{tabular}

Taguchi analysis was performed on the MINITAB 17 program according to the highest-best evaluation method [19]. The $\mathrm{S} / \mathrm{N}$ ratios obtained as a result of the analysis made with the MINITAB program are shown in Table 3.

Basically, analysis of variance rates the variability between groups (differentiation-variance) to the variability between source variables (differentiation-variance). The purpose of the analysis is to determine whether the variation between the welding variables is greater than the variation between the weld strength. For example, the average S/N ratio for shoulder diameter at levels is calculated by averaging the average $\mathrm{S} / \mathrm{N}$ ratios for $1,2,3$, and 4 experiments. $1-4,5-8,9-12$ and $13-16$, respectively. The first line of table 4 shows the average $\mathrm{S} / \mathrm{N}$ ratio for each level of the welding the parameters $[15,16]$.

In Table 4 , the average of $\mathrm{S} / \mathrm{N}$ ratio of the sixteen tests obtained for the tensile strength results was calculated as $19.8 \mathrm{~dB}$. For tensile strength, the $\mathrm{S} / \mathrm{N}$ result graph (Fig. 4) was plotted using the results given in Table 4 . The dotted line shown in the figure is the average of the $\mathrm{S} / \mathrm{N}$ values obtained from the experiments (19.8 dB) [19].
In this graph, the parameters affecting the weld tensile strength were evaluated among themselves and the signal/noise ratios of each parameter were substracted. For example, there is a linear increase in $\mathrm{D} / \mathrm{d}$ ratio, tool rotation speed and feed rate, then a decrease, the point at which the decrease begins is critical for the welding conditions.

Table 4. Average of standard deviation rates of welding tests

\begin{tabular}{|c|c|c|c|c|c|}
\hline \multirow{2}{*}{ Symbol } & Welding & \multicolumn{4}{|c|}{ Average S/N ratio, dB } \\
\cline { 3 - 6 } & parameters & Level 1 & Level 2 & Level 3 & Level 4 \\
\hline A & $\begin{array}{c}\text { Shoulder } \\
\text { diameter, mm }\end{array}$ & 19.84 & 20.00 & 18.15 & 21.15 \\
\hline B & $\begin{array}{c}\text { Shoulder } \\
\text { diameter/pin } \\
\text { diameter ratio }\end{array}$ & 19.24 & 18.97 & 20.70 & 20.22 \\
\hline C & $\begin{array}{c}\text { Tool rotation } \\
\text { speed, rpm }\end{array}$ & 19.65 & 20.22 & 20.48 & 18.79 \\
\hline D & $\begin{array}{c}\text { Feed rate, } \\
\text { mm/min }\end{array}$ & 19.45 & 20.20 & 20.76 & 18.72 \\
\hline
\end{tabular}

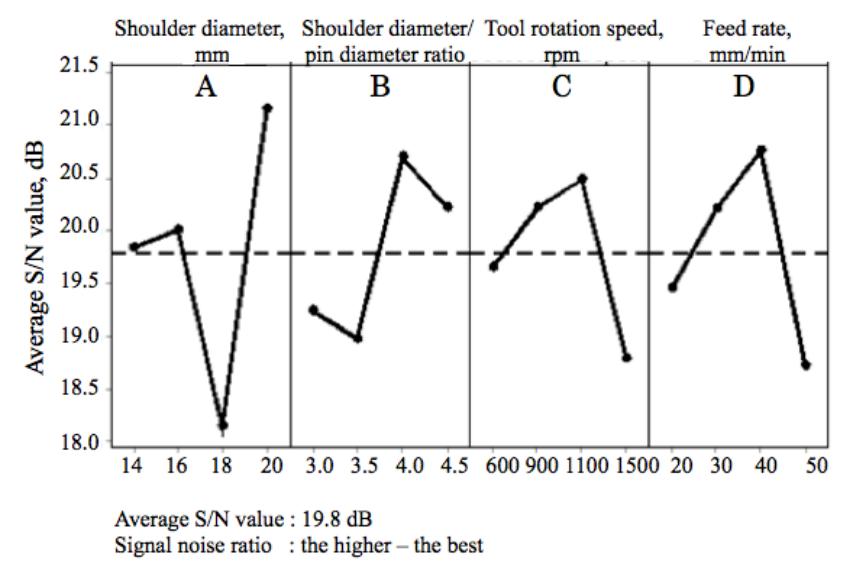

Fig. 4. Mean S/N ratio effect of weld tensile strength [19]

Sudden drop values are very important in terms of results. In addition, we can understand that all source variables can be realized above the average $\mathrm{S} / \mathrm{N}$ value (19.8 dB).

The effect of welding parameters on weld tensile strength in pairs by using average $\mathrm{S} / \mathrm{N}$ values is shown in Fig. 5. The black regions in the graphs show the tensile strength regions above $15 \mathrm{MPa}$. In these graphs, since the other parameters are neglected, only the joint effect of the two weld parameters is understood. From these graphs, detailed information about optimum welding parameters can be obtained. When the black regions are evaluated, it becomes clear that each parameter should be within certain ranges. For example, when the binary diagrams are examined for optimum values of shoulder diameter, it is seen that they are in the $18.2-20.0 \mathrm{~mm}$ range in Fig. $5 \mathrm{a}$, c and $\mathrm{f}$. The tool rotation speed is in the range 1030-1350 rpm in Fig. 5 b, c and e and in feed rate $25-35 \mathrm{~mm} / \mathrm{min}$. must be selected in Fig. 5 d, e and f.

The high welding strength and welding performance is achieved if suitable combinations are provided between the welding parameters. Accurate determination of weld parameter levels can only be done using variance analysis. Analysis of variance (ANOVA) is obtained by calculating the signal to noise $(\mathrm{S} / \mathrm{N})$ ratios by separating the total variability. To find out which welding parameters are 
significant, the quality test is examined with the $\mathrm{F}$ test named Fisher. In the Fisher test, when $\mathrm{F}>4$, it means that the welding parameters have a significant effect on the quality property $[15,16]$.
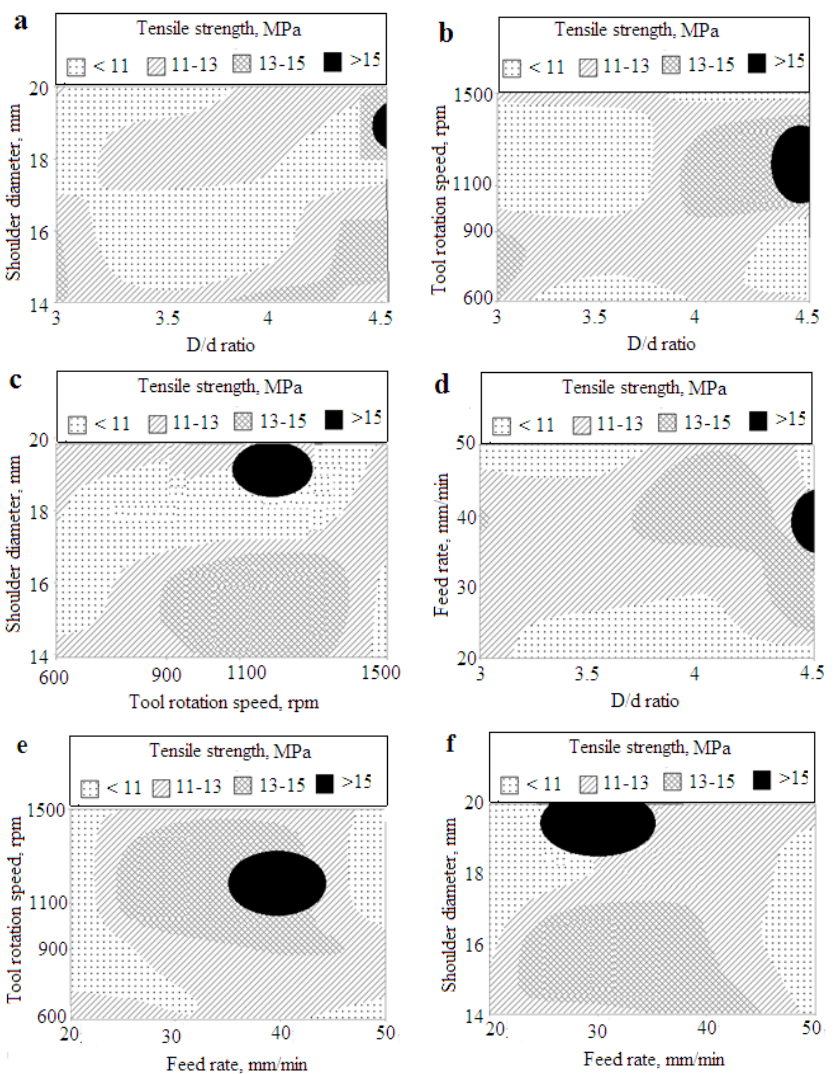

Fig. 5. ANOVA analyses, the optimal welding parameters for tensile strength [19]

As a result of the ANOVA analysis, the effects of welding parameters on FSW are given in Table 5 . Table 5 clearly demonstrates the effect of welding variables on the welding strength in percentage. When we examined the Table 5, it was found that the highest effect was shoulder diameter with $40.81 \%$ and the tool rotation speed was the lowest with $12.42 \%$. Also, looking at the $\mathrm{f}$ value, two parameters were obtained great than 4 .

Shoulder diameter and feedrate are the most important welding parameters. Because F values have been obtained 6.00 and 4.27 respectively. When $F$ value is considered, the fact that the two parameters are above 4 makes the two parameters indirectly effective. If $F$ is less than 4 , we can understand that this factors are insignificant. Because of these results, two parameters should be emphasized and concentrated. Evaluations are made by taking the optimum values for the other two parameters. In Fig. 5, we can select the most suitable welding parameters in more detail to obtain weld strength above $15 \mathrm{MPa}$. S/N and ANOVA results were very close to each other. Confirmation experiments were performed to confirm $\mathrm{S} / \mathrm{N}$ results and ANOVA analyzes. From the $\mathrm{S} / \mathrm{N}$ graph, the welding conditions with the highest $\mathrm{dB}$ values were selected from Fig. 4. Confirmation experiments were carried out under shoulder diameter $20 \mathrm{~mm}$, D/d ratio 4, tool rotation speed $1100 \mathrm{rpm}$ and feed rate $40 \mathrm{~mm} / \mathrm{m}$. It was determined by selecting welding conditions just above the average $\mathrm{S} / \mathrm{N}$ value from the $\mathrm{S} / \mathrm{N}$ graph (Fig. 4) as the initial parameter (A2B4C2D2). For optimum welding conditions, the highest values of the $\mathrm{S} / \mathrm{N}$ graph were taken (A4B3C3D3). Since the initial and optimum welding conditions were not in the sixteen tests, tensile strength and $\mathrm{S} / \mathrm{N}$ values were determined by performing five tests in these conditions. Estimated evaluation for initial and optimum welding conditions was performed in the MINITAB 17 program. As a result of the estimated evaluation, it was determined that tensile strength of 17.30 MPa would be obtained in Table 6 . In the experimental studies conducted under these conditions, weld strength was found to be approximately 16.20 MPa. There was no significant difference between the estimated and the experimental weld strength results. As a result, it has been determined that tensile strength will increase when suitable welding conditions are selected.

Table 5. Analysis of variance (ANOVA) results and welding parameters effect rates

\begin{tabular}{|c|c|c|c|c|c|}
\hline & $\begin{array}{c}\text { Welding } \\
\text { parameters }\end{array}$ & $\begin{array}{l}\text { Degree of } \\
\text { freedom }\end{array}$ & $\begin{array}{l}\text { Sum of } \\
\text { squares }\end{array}$ & $\begin{array}{c}\mathrm{F} \\
\text { value }\end{array}$ & $\begin{array}{c}\text { Effect } \\
\text { ratio, \% }\end{array}$ \\
\hline A & $\begin{array}{l}\text { Shoulder } \\
\text { diameter }\end{array}$ & 3 & 13.35 & 6.00 & 40.81 \\
\hline B & $\begin{array}{l}\text { Shoulder } \\
\text { diameter/pin } \\
\text { diameter } \\
\text { ratio, D/d }\end{array}$ & 3 & 5.72 & 2.94 & 17.49 \\
\hline C & $\begin{array}{l}\text { Tool rotation } \\
\text { speed }\end{array}$ & 3 & 4.06 & 2.10 & 12.42 \\
\hline \multirow[t]{3}{*}{$\mathrm{D}$} & Feed rate & 3 & 8.16 & 4.27 & 24.93 \\
\hline & Error & 3 & 1.42 & 0.77 & 4.34 \\
\hline & Total & 15 & 32.71 & & 99.99 \\
\hline
\end{tabular}

Table 6. Confirmation test results

\begin{tabular}{|l|c|c|c|}
\hline & \multirow{2}{*}{\begin{tabular}{c} 
Initial weld \\
conditions \\
\cline { 3 - 4 }
\end{tabular}} & \multicolumn{2}{|c|}{ Optimum weld conditions } \\
\cline { 3 - 4 } & Experimental) & Predicted & Experimental \\
\hline $\begin{array}{l}\text { Welding conditions } \\
\text { levels }\end{array}$ & A2B4C2D2 & A4B3C3D3 & A4B3C3D3 \\
\hline Weld strength, MPa & $11.60 \mathrm{MPa}$ & $17.30 \mathrm{MPa}$ & $16.20 \mathrm{MPa}$ \\
\hline $\begin{array}{l}\text { Calculated S/N } \\
\text { oran1, dB }\end{array}$ & $21.29 \mathrm{~dB}$ & $28.67 \mathrm{~dB}$ & $27.73 \mathrm{~dB}$ \\
\hline
\end{tabular}

In Fig. 6, the cross-sectional view taken and the regions of the SEM images taken are shown. The friction stir welding consists of three main regions. These regions are composed of nugget zone, thermomechanically affected zone and base material. Based on the results obtained in the evaluation of the optimization, SEM images were taken from the experiments with the initial parameter and the prediction parameters.

SEM images of the nugget zone are shown in Fig. 7. SEM images taken from joints made with the initial parameters and experimental parameters are given in Fig. $7 \mathrm{a}$ and b, respectively. The most obvious difference between the initial parameter and the experimental parameter as can be clearly seen from the SEM image, it is the formation of too much circulation movement in the nugget zone.

In the nugget zone, too much circulation has occurred because the tool has been left for too long and the feed rate is slow. Circulation occurred in the nugget zone because the tool was left too long and the feed rate was low. Due to these situations, excessive temperature and material overflow 
occurred in the nugget zone. Therefore, the strength values are low. Unless the welding parameters are compatible with each other, as seen in Fig. 7 a regular structure does not occur in the nugget zone.

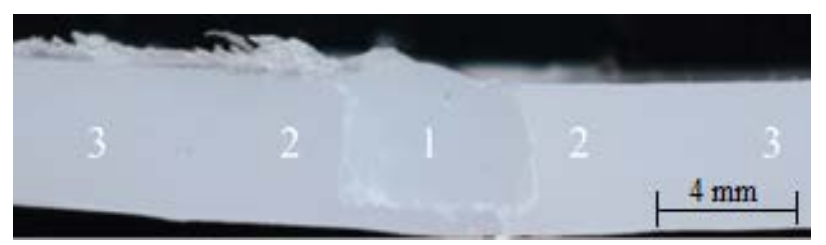

Fig. 6. The cross-sectional view taken and the regions of the SEM images: 1 -nugget zone; 2 -thermomechanically affected zone; 3 -base material

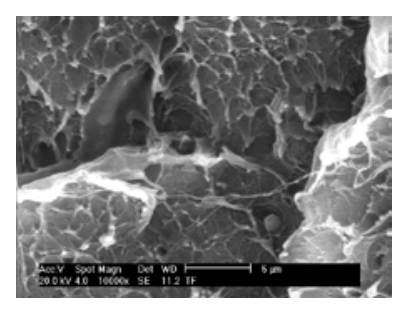

a

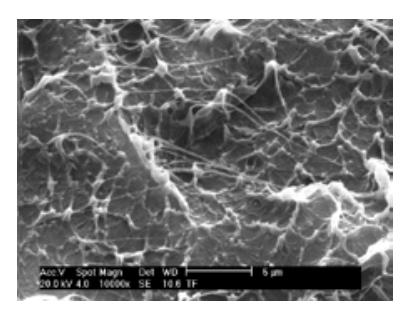

b
Fig. 7. SEM images of the nugget zone in the FSW: a-initial parameters; $b$ - experimental parameters

In Fig. 7 b, the structure in the nugget zone has become more orderly since the welding conditions are more favorable. Since there is no excessive fluctuation in the nugget zone, the highest welding strength is obtained. The most important reason for this is the appropriate selection of welding conditions. The rate of feed rate increases with respect to the initial parameter and excessive heat does not occur.

Thermomechanically affected region are directly affected by the adverse effects occurring in the nugget zone. Excessive heat in the nugget zone, excessive melting of the material and improper feed rate affect. In Fig. 8 a, when the structure is examined, there is a lot of structure irregularity due to the stirring effect. Once the material in the nugget zone has melted, it is necessary to move the material along the welding seam at the appropriate feed rate. When the feed rate is not selected properly, excessive heat generation or insufficient penetration, discontinuity occurs.

In Fig. 8, the SEM image of the thermomechanically affected region of the weld made is given. Due to the low advance speed of the welding set, a very irregular and wavy structure was formed in the ingot area (Fig. 8 a). In addition, small shoulder diameter and material overflow led to these results. The welding parameters here are close to the average $\mathrm{S} / \mathrm{N}$ value.

When welds made with the first parameter and optimum parameters are examined the structure, the differences arising from the welding set and welding parameters can be clearly seen (Fig. $8 \mathrm{a}$ and b). The structure in Fig. 8 b shows that fluctuation and mixing are more homogeneous. In such a structure, high welding strength and weld performance are always obtained.

The hardness values of the weld measured on the crosssectional view surface are given in Table 7 . Three hardness values were taken from each region along a line. Their average is given in the Table 7 . Considering the hardness values, the hardness of the nugget zone was lower than the base material of joining under initial conditions. Because with excessive contact of the welding tool to the material in the nugget zone during welding has caused mechanical scission here.

Table 7. The Shore-D hardness values of the initial and prediction parameters

\begin{tabular}{|l|c|c|c|c|c|}
\hline & 3 & 2 & 1 & 2 & 3 \\
\hline Experimental parameters & 53 & 56 & 52 & 54 & 52 \\
\hline Initial parameters & 52 & 48 & 47 & 49 & 53 \\
\hline
\end{tabular}

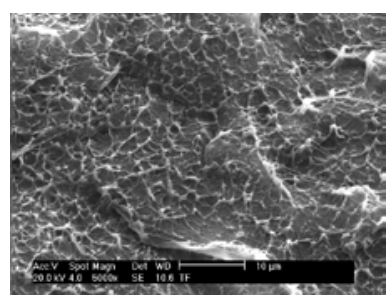

a

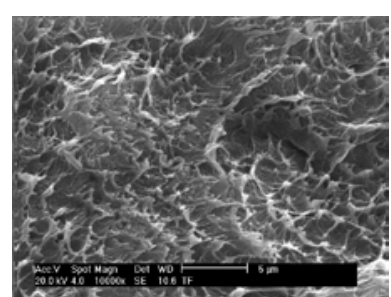

b
Fig. 8. SEM images of thermomechanically affected zone in the FSW: a -initial parameters; $b$ - experimental parameters

The mechanical cleavage that occurred in excessive heat generation has affected both the weld strength and the hardness here. In welding performed under experimental parameters, the welding tool did not remain in much contact in the nugget zone due to the ideal feed rate and tool rotation speed. Therefore, nugget zone heat and TMAZ heat have occured ideally in the welding direction. Because the hardness difference here occurred as a result of obtaining enough heat and distributing this heat homogeneously in the direction of welding. When the hardness changes in the initial and experimental conditions are examined, it is seen that different the hardness value in the weld regions are realized.

The basic condition in friction stir welding is heat generation and keeping this heat in the weld zones in a uniform manner both with the welding tool and with the welding parameters and to ensure its spread. If these conditions are provided, it is clearly seen that the hardness in the nugget zone increases from 47 to 53 shore-D hardness. In addition, the hardness changed occurred more in the TMAZ zone. The hardness increased from 48 to 56 shore-D value. There was no change in the hardness of the welds made in the initial parameters. Here, the mechanical scission started and continued. It shows that in welds in experimental parameters, heat is provided along the weld line without mechanical scission. In this way, the increase in hardness value was inevitable and ideal joining was achieved. When the optimization results are examined, it is seen that ideal joining will be achieved as a result of the most suitable welding conditions. In order to obtain the ideal heat and control the temperature, it has been revealed that it is affected by about $60 \%$ tool design and $40 \%$ welding parameters. At the same time, these conditions affect the hardness values. It has been determined that the welding seam is formed flawlessly provided that the appropriate conditions are provided.

\section{CONCLUSIONS}

The friction stir welding process of high density 
polyethylene sheets has been successfully combined. Evaluations were made using Taguchi optimization and ANOVA analysis. Shoulder diameter has been determined as the most important factor affecting weld tensile strength and weld properties at a rate of approximately $40.81 \%$. Among the parameters selected for friction stir welding, it has been determined that the most weld quality and highest tensile strength will be obtained in welding conditions with shoulder diameter of $20 \mathrm{~mm}, \mathrm{D} / \mathrm{d}$ ratio 4, tool rotation speed $1100 \mathrm{rpm}$ and feed rate $40 \mathrm{~mm} / \mathrm{min}$. This result has been confirmed both experimentally and by estimation method. Thanks to optimization, tensile strength increased by approximately $30 \%$ and hardness values increased by approximately $15 \%$. From the Anova analysis, it was found that shoulder diameter and feed rate had an effect of approximately $60 \%$ on the joining process. In addition, the importance of the selection of these two parameters in polyethylene friction stir welding has become clear. When feed rate - tool rotation speed is selected at the lowest and highest values, it has been observed that it has a negative effect on tensile strength, weld quality and hardness values. The accuracy of optimization and anova analysis should be $95 \%$ to $100 \%$. $5 \%$ error rate is acceptable. In our study, this rate was obtained $96 \%$.

\section{Acknowledgments}

This work was supported by Scientific Research Project Program of Marmara University (Project No. FEN-A110915-0433). The authors are grateful to Marmara University for their financial support and the provision of laboratory facilities.

\section{REFERENCES}

1. Thomas, W.M., Nicholas, E. Friction Stir Welding for the Transportation Industries Materials Design 18 1997: pp 269-273.

2. Khan, N. Z., Siddiquee, A. N., Khan, Z. A., Mukhopadhyay, A. K. Mechanical and Microstructural Behavior of Friction Stir Welded Similar and Dissimilar Sheets of AA2219 and AA7475 Aluminium Alloys Journal of Alloys and Compounds 695 2017: pp. 2902-2908. https://doi.org/10.1016/j.jallcom.2016.11.389

3. Gangwar, K., Ramulu, M. Friction Stir Welding of Titanium Alloys: A Review Materials Design 141 2018: pp. 230-255.

https://doi.org/10.1016/j.matdes.2017.12.033

4. Serindag, H.T., Kiral, B.G. Friction Stir Welding of AZ31 Magnesium Alloys-A Numerical and Experimental Study Latin Amerikan Journal Solids and Structure 14 2017: pp. $113-130$. https://doi.org/10.10590/1679-78253162

5. Nagabharam, P., Srikanth Rao, D., Manoj, J., Kumar, N. Investigation of Mechanical Properties of Friction StirWelded
Pure Copper Plates Materials Todays: Proceedings 5 (1) 2018: pp. $1264-1270$.

http://doi.org/10.1016/j.matpr.2017.11.210

6. Geçmen, I., Çatalgol, Z., Bilici, M.K. Effect of Welding Parameters on Mechanical Properties and Microstructure of Friction Stir Welded Brass Joints Matériaux \&Techniques 2019: pp. 606-618.

https://doi.org/10.1051/mattech/2018060

7. Tiwari, A., Singh, P., Biswas, P., Sachin, D. Friction Stir Welding of Low-Carbon Steel International Conference on Mechanical Engineering 2018: pp. 209-226.

8. Salih, O.S., Hengan, O., Sun, W., McCartney, D.G. Review of Friction Stir Welding of Aluminium Matrix Composites Materials Design 141 2015: pp. 61-71. https://doi.org/10.1016/j.matdes/2015.07.071

9. Haldar, N., Datta, S., Kumar, R. Experimental Studies on Friction Stir Welding of AA6061 Using Inconel 601Tool Journal Brazilian Society Mechanical Science Engineering 40 2018: pp. $440-448$. https://doi.org/10.1007/s40430-018-1378-z

10. Paoletti, A., Lambiase, F., Di Ilio, A.Optimization of Friction Stir Welding of Thermoplastics Procedia CIRP 33 2015: pp. $562-567$. https://doi.org/10.1016/j.procir.2015.06.078

11. Jayaraman, M., Sivasubramanian, V.,

Sivasubramanian, R., Lakshminarayanan, A.K. of Cast Aluminium Alloy A319 by Taguchi Method Journal of Scientific and Industrial Research 68 2009: pp. 36-43. http://hdl.handle.net/123456789/2786

12. Sahu, P.K., Pal, S. Effect of FSW Parameters on Microstructure and Mechanical Properties of AM20 Welds Materials and Manufacturing Processes 33 2018: pp. $288-298$. https://doi.org/10.1080/10426914.2017.1279295

13. Rabby, R.E., Reynolds, A.P. Some Effects of Tool Geometric Features on Friction Stir Weld Response Parameters Science and Technology Welding Joining 23 2018: pp. 575-584. https://doi.org/10.1080/13621718.2018.1430009

14. Squeo, E.A., Bruno, G., Guglielmotti, A., Quadrini, F. Friction Stir Welding of Polyethylene sheets, The Annals of "Dunarea de Jos" University of Galati Fascicle, Technology Machine Builds 5 2009: pp. 241-245.

15. Ross, P.J. Taguchi Techniques for Quality Engineering McGraw Hill, New York 1988.

16. Peace, G.S. Taguchi Methods.Addison-Wesley, New York, 1993.

17. ASTM D638 Standard Test Method for Tensile Testing of Plastics.

18. ASTM D 2240 Standard Test Method for Rubber Property Durometer Hardness.

19. Minitab User Manual (Release 17). Making Data Analysis Easier. MINITAB Inc. State College, PA: USA. 2018.

(c) Bilici et al. 2021 Open Access This article is distributed under the terms of the Creative Commons Attribution 4.0 International License (http://creativecommons.org/licenses/by/4.0/), which permits unrestricted use, distribution, and reproduction in any medium, provided you give appropriate credit to the original author(s) and the source, provide a link to the Creative Commons license, and indicate if changes were made. 